\title{
Exhaled and Nasal Nitric Oxide - Impact for Allergic Rhinitis
}

\author{
Martina ANTOSOVA ${ }^{1}$, Alica BENCOVA ${ }^{2}$, Daniela MOKRA ${ }^{1,3}$, Jana PLEVKOVA ${ }^{4}$, Lubomir \\ PEPUCHA $^{5}$, Tomas BUDAY ${ }^{4}$
}

${ }^{1}$ BioMed Martin, Division of Respirology, Comenius University in Bratislava, Jessenius Faculty of Medicine in Martin, Slovak Republic, ${ }^{2}$ Clinic of Pneumology and Pthiseology, Comenius University in Bratislava, Jessenius Faculty of Medicine \& University Hospital in Martin, Slovak Republic, ${ }^{3}$ Department of Physiology, Comenius University in Bratislava, Jessenius Faculty of Medicine in Martin, Slovak Republic, ${ }^{4}$ Department of Pathophysiology, Comenius University in Bratislava, Jessenius Faculty of Medicine in Martin, Slovak Republic, ${ }^{5}$ Centre for Science, Research and Development Support, Comenius University in Bratislava, Jessenius Faculty of Medicine in Martin, Slovak Republic

Received October 15, 2019

Accepted November 28, 2019

\section{Summary}

FeNO measurement is a validated non-invasive technique, which is used for diagnosis and monitoring of asthma. It would be desirable to find a reliable method to monitor allergic rhinitis (AR) via measurement of FeNO, and/or nasal nitric oxide (nNO). The aim of our study was the assessment of the efficacy of FeNO and $\mathrm{nNO}$ as markers in AR treatment. FeNO and nNO were measured with the portable NO analyser (NIOX MINO ${ }^{\circledR}$ ) in healthy participants and in patients with AR. The patients were examined during the pollen season and out of it. The effect of local corticosteroids and antihistamine therapy was observed in patients with AR during pollen season after three weeks of therapy. There are significant differences between FeNO and nNO in patients with AR compared to healthy controls at all set points of measurements. While FeNO responded well to the treatment with both antihistamines and combined therapy, nNO decreased only after combined therapy with antihistamines and nasal corticosteroids. nNO monitoring alone is not a suitable method to monitor inflammation of the upper airways in AR and its suppression by anti-allergic treatment and should be correlated with other markers as FeNO or symptom scores.

\section{Key words}

Nitric oxide • Allergic rhinitis • Inflammation • Pharmacotherapy

\section{Corresponding author}

Tomas Buday, Department of Pathophysiology, Jessenius Faculty of Medicine in Martin, Comenius University in Bratislava, Mala Hora 4C, 03601 Martin, Slovak Republic. Email: tomas.buday@uniba.sk

\section{Introduction}

Allergic rhinitis (AR) is the most common allergic disease in both adult and paediatric population. It is frequently under-diagnosed, and therapy is often insufficient. Untreated AR is a risk factor for onset and progression of lower airway diseases, therefore effective treatment of the upper airway inflammation is a preventive measure towards lower airways pathology (Corren 1998).

Nitric oxide (NO) plays a substantial role in airways. It regulates bronchial muscle tone, blood flow and immune response in the lower airways, controls the motion of cilia and regulates defence processes in the upper airways (Struben et al. 2006, Antosova et al. 2017a). Its concentration increases due to eosinophilic inflammation in the airways what makes the detection of NO perfect diagnostic tool (Jatakanon et al. 1998).

While method of exhaled NO (FeNO) measurement reached the clinical practice relatively quickly becoming a reliable tool in the management of asthma (Balbi et al. 2007), detection of nNO is not a routine diagnostic method so far, except ciliary disorders (Leigh et al. 2013). The reason is an ambiguous approach to detection technology, the difference in devices used for detection, insufficient information about factors that affect nNO (Jorissen et al. 2001) together with high inter-individual variability, over-time variation 
and lack of universal standardization of testing procedure (Kharitonov et al. 1997). There is evidence about the role of NO in the pathogenesis of allergic rhinitis and asthma (Alving et al. 1993, Bergmann-Hug et al. 2009), however, detection of $\mathrm{nNO}$ as a marker in allergic rhinitis is still not validated (Antosova et al. 2017b). Some authors suggest, that monitoring of $\mathrm{nNO}$ as non-invasive and easy-to-perform techniques can be useful to monitor $\mathrm{AR}$ and its clinical course. Our study was aimed to measure FeNO and nNO in healthy volunteers and patients with allergic rhinitis to assess effects of allergen exposure and pharmacotherapy (antihistamines and local corticosteroids) on levels of both FeNO and $\mathrm{nNO}$ to ascertain the reliability of $\mathrm{nNO}$ detection in management of seasonal AR.

\section{Methods}

\section{Study population}

The study population consisted of 100 participants. All participants recruited to the control group $(n=50)$ have met the inclusion criteria, they were older than 18 years, have no chronic respiratory disease, no lower airway symptoms (cough, breathlessness, chest tightness etc.), no acute respiratory infection within 3 weeks prior the test, non-smokers with the willingness to cooperate.

All participants with allergic rhinitis recruited to the "rhinitis" group $(n=50)$ have met the inclusion criteria, they were older than 18 years, non-smokers, with positive skin prick tests to common seasonal allergens, seasonal presence of the upper airway/eye symptoms, pharmacotherapy with antihistamines and/or local corticosteroids with willingness to cooperate. Characteristics of the study population are summarized in Table 1.

Measurement

The study was approved by the Ethical
Committee at Jessenius Faculty of Medicine and Martin University Hospital and informed consent was obtained from all participants after the purpose of the study had been explained.

Measurements of $\mathrm{FeNO}$ and $\mathrm{nNO}$ were performed by analyser NIOX MINO $^{\circledR}$ (Aerocrine, Sweden), specific sensors and filters were used for FeNO and nNO measurements. Procedures were performed according to ATS \& ERS guidelines. Subjects were educated about the methods and practical performance of the test, which was carried out in a sitting position after $15 \mathrm{~min}$ of rest in the laboratory. In case of FeNO, subjects inhaled air without NO (NO $<5 \mathrm{ppb})$ via mouthpiece with filter until they reached total lung capacity (TLC) and this inhalation was followed by exhalation via mouthpiece lasting up to $10 \mathrm{~s}$ with at least $6 \mathrm{~s}$ plateau of NO values detected automatically by the device. Exhalation rate was maintained at the flow of $50 \mathrm{ml} / \mathrm{s}$. Values of FeNO were expressed in ppb (parts per billion) (ATS/ERS 2005).

Detection of $\mathrm{nNO}$ was performed using the research application of NIOX MINO. nNO was measured in each nostril (RnNO - right nostril, LnNO - left nostril) during passive aspiration of air via special ergonomic olive (filter) at the flow $5 \mathrm{ml} / \mathrm{s}$, with tidal breathing technique with velum closure. Values of nNO from right and left nostril were averaged and expressed in $\mathrm{ppb}$.

Patients with allergic rhinitis were examined out of pollen season, during the pollen season (March - June) without treatment (untreated), during the pollen season after at least 3 weeks of treatment with oral antihistamines and/or nasal corticosteroids. Data from healthy controls were taken irrespective to pollen season. All participants were instructed to avoid factors affecting FeNO and nNO a day prior to the measurement. All participants were examined after 10 minutes of rest, at least 1 hour after the food intake and in the same time of the day respecting diurnal variations of NO production all patients were examined about 10 a.m.

Table 1. Characteristics of the study population

\begin{tabular}{lcccc}
\hline Participants & n & Age (years) & Weight (kg) & Height (cm) \\
\hline $\begin{array}{l}\text { control }- \text { women } \\
\text { control }- \text { men }\end{array}$ & 30 & $21.06 \pm 3.72$ & $58.7 \pm 7.9$ & $168.10 \pm 6.4$ \\
\hline rhinitis - women & 20 & $21.30 \pm 1.75$ & $78.9 \pm 11.5$ & $182.7 \pm 6.3$ \\
rhinitis - men & 35 & $39.00 \pm 10.92$ & $64.3 \pm 10.2$ & $165.2 \pm 5.6$ \\
\hline
\end{tabular}




\section{Statistical analysis}

Comparison of the average FeNO and nNO values between controls and seasonal AR group and also FeNO and nNO values measured out of the pollen season, then after allergen exposure and after treatment was performed by the t-test and one way-ANOVA. Values of $\mathrm{p}<0.05$ were considered as statistically significant. Data were processed by the SPSS software and Microsoft Excel.

\section{Results}

The effect of allergic airway inflammation and medication on FeNO and nNO levels

The value of FeNO in the AR group measured out of the pollen season did not differ from the values of the control group. During the pollen season, after the exposure to aeroallergens and the onset of nasal symptoms the data for FeNO increased significantly to $20.5 \mathrm{ppb},(\mathrm{p}=0.002)$ even the participants did not have any lower airways symptoms (Table 2 and 3 ).

Similarly, nNO levels were not different between healthy controls and allergic subjects out of the pollen season. Measurement was performed in both nostrils (right - RnNO and left LnNO) concerning the nasal cycle and then averaged. There were small, however not significant differences between the left and right nasal passages both in control and allergic rhinitis groups.

Values of $\mathrm{nNO}$ in subjects with allergic rhinitis were significantly higher after the allergen exposure during the pollen season $(\mathrm{p}<0.001)$, for a summary, see Table 2.

All participants with allergic rhinitis were treated with anti-allergic drugs $(\mathrm{n}=50,35 \mathrm{~F}, 15 \mathrm{M}) .24$ participants $(17 \mathrm{~F}, 7 \mathrm{M})$ were treated by $\mathrm{H} 1$-antihistamines (desloratadine, levocetirizine and fexofenadine), and 26 patients $(18 \mathrm{~F}, 8 \mathrm{M})$ with a combination of $\mathrm{H}_{1}$-antihistamines and local nasal corticoids treatment (beclomethasone, fluticasone and mometasone). Pooled data in the AR group failed to show any significant differences in FeNO and nNO after three weeks of treatment (Table 3).

Table 2. The effect of allergic airway inflammation on FeNO and nNO levels

\begin{tabular}{lcc}
\hline & Healthy controls (average values) & $\begin{array}{c}\text { Allergic rhinitis pooled data } \\
\text { (average values) }\end{array}$ \\
\hline $\boldsymbol{F e N O}(\boldsymbol{p p b})$ & $16.95(6.00-38.00)$ & $17.00(7-70)$ \\
out of the season & $($ n.s. $)$ & $22.50(7-72) *$ \\
allergen exposure & $($ n.s. $)$ & $17.00(6-65)(\mathrm{n} . \mathrm{s})$. \\
3 wks of treatment & & $620(402-1320) *$ \\
$\boldsymbol{n} \boldsymbol{O}(\boldsymbol{p p b})$ & $393(150-963)$ & $824(443-2003 * *$ \\
out of the season & $($ n.s. $)$ & $834(473-1131)(\mathrm{n} . \mathrm{s})$. \\
allergen exposure & $($ n.s. $)$ & \\
3 wks of treatment & & \\
\hline
\end{tabular}

$*(p<0.05)$ vs controls, $* *(p<0.01)$ vs controls, (n.s.) without significant difference

Table 3. The effect of anti-allergic therapy on FeNO and nNO in allergic rhinitis subjects

\begin{tabular}{lccccc}
\hline & & FeNO (ppb) & FeNO (ppb) & nNO (ppb) & nNO (ppb) \\
& $\mathbf{n}$ & $\begin{array}{c}\text { Allergen exposure } \\
\text { 3-week treatment }\end{array}$ & Allergen exposure & 3-week treatment \\
\hline AR Pooled data & 50 & $21(7-72) *$ & $17(6-65)($ n.s.) & $824(443-2003)($ n.s.) & $834(473-1131)($ n.s.) \\
AR AH treatment & 24 & $22(7-68) *$ & $18(7-54) \# \#$ & $737(433-1031)($ n.s.) & $722(421-1075)(\mathrm{n} . \mathrm{s})$ \\
AR AH+CS treatment & 26 & $19(10-72) *$ & $15(6-65) \# \#$ & $875(489-2003)($ n.s.) & $813(315-1705) \# \#$ \\
\hline
\end{tabular}

$*(p<0.05)$ vs controls, \#\# ( $p<0.05)$ vs before treatment, (n.s.) without significant difference, AR pooled data - data of all subjects regardless the treatment, 3 wks $\mathrm{AH}-3$ weeks on antihistamines, 3 wks $\mathrm{AH}+\mathrm{CS}-3$ weeks on oral antihistamines in combination with nasal corticosteroids 
Further analysis of results for the effect of $\mathrm{H}_{1}-$ antihistamines proved a significant decrease of FeNO as a response to three weeks' treatment. Antihistamines surprisingly did not affect the level of nNO even after separate analysis for antihistamines and corticoids (Table 3). Combination of $\mathrm{H}_{1}$-antihistamines and nasal corticoids significantly reduced $\mathrm{FeNO}$ and $\mathrm{nNO}$ values (Table 3) pointing towards the better therapeutic effect of combined therapy for both upper and lower airways.

\section{The effect of gender on FeNO and $n N O$ values}

Gender differences in FeNO levels were also detected during data analysis in both control and rhinitis groups with women having a higher concentration of FeNO 19.5 (9-38) ppb vs 15.2 (6-34) ppb, (p<0.05). This pattern continues throughout all measured points in both groups and women have always higher FeNO than men with the highest significance obtained after the treatment $(p<0.01)$ indicating that women with AR have a better response to the treatment than men. No gender differences in nNO were observed neither for control nor allergic rhinitis groups (data not shown).

\section{Discussion}

Diagnosis and therapeutic management of allergic airways disease require as precise monitoring of inflammation as possible, therefore, we tested whether nNO could be a reliable marker of AR. Instead of wellestablished reliability of FeNO measurement in asthma, measurement of nNO is under discussion (Kharitonov et al. 1997, Henriksen et al. 1999). The idea of nNO measurement is based on "one airway - one disease" concept. Even though asthma and allergic rhinitis vary with the clinical phenotype, Th1/Th2 signalling, main cellular and biochemical profile, they share the main pathogenetic features (Bachert et al. 2002). One of them is eosinophilic inflammation that increases the expression of iNOS, leading to increased production of NO (Williamson et al. 2010).

Studies about $\mathrm{nNO}$ as a marker of allergic rhinitis share conflicting evidence and measurement of nNO is still not validated for routine clinical use (Lee et al. 2012). Low reliability of nNO measurement is caused mainly by extremely high variability of nNO values which range from 200 to $2000 \mathrm{ppb}$ (Serrano et al. 2004).

The aim of our study was to analyse levels of nNO and FeNO in subjects with $\mathrm{AR}$ and to observe the effect of medication during the pollen season on those levels. Our study showed that FeNO levels did not differ between control and allergic subjects out of the pollen season, but are significantly elevated after the allergen exposure during the season even allergic subjects did not have any symptoms from the lower airways. This finding indicates the presence of inflammation in the lower airways at the sub-clinical level (Corren, 1998, Polosa et al. 2000, Bachert et al. 2002). Increased levels of FeNO in adults with AR were reported by Downie et al. (2004), and other authors (Gratziou et al. 2001, Linhares et al. 2011). Control of inflammation in the lower airways in allergic subjects is important to prevent the onset of complication in the lower airways. nNO values differed significantly between healthy control subjects and allergic subjects also out of the season, with significant elevation of $\mathrm{nNO}$ production after the allergen exposure.

The increase of FeNO and nNO with the start of the pollen season is highly indicative of the increased activity of iNOS, as its expression and activity increases due to allergic inflammation in the airways (Arnal et al. 1997). Significant increase of FeNO $(\mathrm{p}<0.001)$ and $\mathrm{nNO}$ $(\mathrm{p}<0.001)$ indicates the presence of inflammation in both compartments - upper and lower airways in subjects with allergic rhinitis.

Our data showed that nNO levels are significantly higher in allergic subjects also out of the pollen season, which is in conflict with other studies which failed to detect elevated levels of $\mathrm{nNO}$ in allergic subjects out of the season (Jilma et al. 1996, Henriksen et al. 1999), however, these studies did not consider the presence of perennially sensitized subjects, which may contribute to such findings.

Gender-related differences were found in the FeNO, but not in the nNO levels. Our data are in agreement with previously published results for both FeNO and nNO (Palm et al. 2003). These gender differences in the FeNO were for the first time noticed by Taylor et al. (Taylor et al. 2006), in a sample consisting of nearly 900 participants, suggesting gender being an important determining factor of FeNO values. Based on the literature data, nNO does not show gender differences (Lee et al. 2012) and our data are in agreement with these findings. The difference can be a consequence of different sensitivity of NO synthase isoforms to oestrogen. While the FeNO reflects mainly the activity of iNOS, nasal NO is a product of more isoforms (Yuksel et al. 2008). Gender-specific findings in our allergic subjects must be interpreted with caveats, because of the composition of allergic groups where majority of subjects 
are women. A higher proportion of men would perhaps bring more clarity to these results.

nNO was measured in both nostrils and then averaged. It is important to notice that there were no differences in $\mathrm{nNO}$ levels measured in the right versus left nostril in our subjects. The side-related differences may be a consequence of e.g. impaired communication of the nasal cavity with sinuses at one side due to mucosal swelling or some other types of obstruction in osteomeatal complex, like hyperplastic mucosa, septal deviation, concha bullosa etc. The role of the nasal cycle is important because it can influence the detection process.

The main objective of our work was to assess the response of FeNO and nNO to medication. The guidelines recommend using two main types of medication - antihistamines and nasal corticosteroids. Antihistamines act as inverse agonists of histamine receptors, reducing histamine-induced signalling and the majority of the symptoms (Wang 2002). Corticosteroids reduce eosinophilic inflammation by rather a complex effect (Basyigit et al. 2004). Subjects of the rhinitis group were divided into two groups. First one was treated by oral $\mathrm{H}_{1}$-antihistamines only, while the second group was treated by a combination of oral $\mathrm{H}_{1}$-antihistamines and nasal corticosteroids. Our subjects were not stratified according to the symptoms severity, because it is known that magnitude of symptoms does not correlate with detected nNO (Lee et al. 2012), e.g. patients with massive mucosal oedema and nasal discharge, or eventually patients with occlusion of sinuses have low levels of nNO despite the high intensity of inflammation in the upper airways.

The results showed that monotherapy by $\mathrm{H}_{1}$-antihistamines reduced significantly the levels of FeNO, but it did not have any effect on nNO. The effect of $\mathrm{H}_{1}$-antihistamines on $\mathrm{FeNO}$, but not on $\mathrm{nNO}$ was gender-specific. Studies showed that antihistamines directly downregulate the expression of iNOS protein and modulate its activity (Yamada et al. 2012). Poor effect of $\mathrm{H}_{1}$-antihistamines on $\mathrm{nNO}$ may indicate either ineffective treatment of upper airway inflammation or poor relevance of $\mathrm{nNO}$ detection. We speculate that even though the medication caused symptom relief, it was not effective enough to fully suppress eosinophilic inflammation in the nasal cavity and sinuses. Duration of the treatment period was also questionable, but according to the guidelines for clinical trials in allergic rhinitis, the optimal duration of studies assessing treatment efficacy is 2 weeks, and longer study periods are not likely to add meaningfully to the assessment of drug efficacy (Krouse et al. 2005).

Physicians prefer combined treatment with oral antihistamines and local corticosteroids regardless of the magnitude of AR (Navarro et al. 2011, Yamada et al. 2012). Treatment by the combination of antihistamines and nasal corticosteroids led to the significant decrease of FeNO and nNO $(\mathrm{p}<0.05)$ and this effect was more significant for women $(p<0.001)$. These results confirm previous findings that treatment of inflammation in the upper airways leads also to the suppression of inflammation in the lower airways. However, there are studies which failed to show the effect of nasal corticosteroid treatment on nNO levels (Lundberg et al. 1997, Maniscalco et al. 2001). This conflicting result may not be related strictly to the nNO production, but they are very likely influenced by other factors, such as diffusion impairment, extensive mucus production, mucosal oedema, impaired communication with sinuses, or occlusion of the nostril and application of decongestants (Olin et al. 1998). In the nose, $\mathrm{nNO}$ is produced by constitutive NO synthase along with the iNOS, which is inhibited by corticosteroids. Therefore, high levels of nNO after corticosteroid treatment could be also explained by the involvement of other isoforms of NO synthase (Olthoff et al. 2002, Struben et al. 2006).

Inflammation itself could be the factor increasing elimination of $\mathrm{nNO}$ by increased mucosal blood flow and vascular permeability in the acute phase of an allergic reaction (Henriksen et al. 1999). There are also studies documenting the elevation of nNO levels after corticosteroid treatment in participants with chronic inflammation and nasal polyps. Reduction of inflammation and mucosal swelling led to the opening of the osteomeatal complex, with increased contribution of NO produced in sinuses to total nNO values (Wilson et al. 2000).

While the measurement of FeNO is quick, easyto-perform, safe and non-invasive technique for the monitoring of the lower airway inflammation, detection of nNO does not seem to be the optimal method for monitoring of eosinophilic inflammation in the nose and sinuses and the reasons are many. The most important is a finding that the severity of nasal mucosal inflammation does not correlate with levels of detected nNO. Even though $\mathrm{nNO}$ levels are increased in allergic subjects during the pollen season, the values are characterized by high variability and do not respond to antihistamine treatment. Even they do respond to combined therapy, 
there are still many factors related to inflammation (mucosal blood flow, mucus layer, diffusion problems, communication with sinuses, other than iNOS sources of nitric oxide in the upper airways) (Lundberg et al. 1997, Olin et al. 1998, Wilson et al. 2000, Maniscalco et al. 2001) along with high range of reference values and inter-individual variability, which make the nNO detection method unreliable in management of allergic rhinitis.

\section{Conflict of Interest}

There is no conflict of interest.

\section{Acknowledgements}

This work was supported with Centre for Experimental and Clinical Respirology (ITMS code of Projects 26220120004 and 26220120034), co-financed from EU sources. The authors declare no conflicts of interest in relation to this article.

\section{References}

ALVING K, WEITZBERG E, LUNDBERG JM: Increased amount of nitric oxide in exhaled air of asthmatics. Eur Respir J 6: 1368-1370, 1993.

ANTOSOVA M, MOKRA D, PEPUCHA L, PLEVKOVA J, BUDAY T, STERUSKY M, BENCOVA A: Physiology of nitric oxide in the respiratory system. Physiol Res 66 (Suppl 2): S159-S172, 2017a. https://doi.org/10.33549/physiolres.933673

ANTOSOVA M, MOKRA D, TONHAJZEROVA I, MIKOLKA P, KOSUTOVA P, MESTANIK M, PEPUCHA L, PLEVKOVA J, BUDAY T, CALKOVSKY V, BENCOVA A: Nasal nitric oxide in healthy adults - reference values and affecting factors. Physiol Res $66 \quad$ (Suppl 2): S247-S255, $2017 \mathrm{~b}$. https://doi.org/10.33549/physiolres.933680

ATS/ERS Recommendations for standardized procedures for the online and offline measurement of exhaled lower respiratory nitric oxide and nasal nitric oxide, 2005. Am J Respir Crit Care Med 171: 912-930, 2005. https://doi.org/10.1164/rccm.200406-710ST

ARNAL JF, DIDIER A, RAMI J, M'RINI C, CHARLET JP, SERRANO E, BESOMBES JP: Nasal nitric oxide is increased in allergic rhinitis. Clin Exp Allergy 27: 358-362, 1997. https://doi.org/10.1111/j.13652222.1997.tb00719.x

BACHERT C, VAN CAUWENBERGE P, KHALTAEV N, BOUSQUET J, WORLD HEALTH ORGANIZATION: Allergic rhinitis and its impact on asthma. Allergy 57: 841-855, 2002. https://doi.org/10.1034/j.13989995.2002.23625.x

BALBI B, PIGNATTI P, CORRADI M, BAIARDI P, BIANCHI L, BRUNETTI G, RADAELI A, MOSCATO G, MUTTI A, SPANEVELLO A, MALERBA M: Bronchoalveolar lavage, sputum and exhaled clinically relevant inflammatory markers: values in healthy adults. Eur Respir J 30: 769-781, 2007. https://doi.org/10.1183/09031936.00112306

BASYIGIT I, YILDIZ F, OZKARA SK, BOYACI H, ILGAZLI A: Inhaled corticosteroid effects both eosinophilic and non-eosinophilic inflammation in asthmatic patients. Mediators Inflamm 13: 285-291, 2004. https://doi.org/10.1080/09629350400003118

BERGMANN-HUG K, WIRTH R, HENSELER M, HELBLING A, PICHLER WJ, SCHNYDER B: Effect of natural seasonal pollen exposure and repeated nasal allergen provocations on elevation of exhaled nitric oxide. Allergy 64: 1629-1634, 2009. https://doi.org/10.1111/j.1398-9995.2009.02087.x

CORREN J: The impact of allergic rhinitis on bronchial asthma. J Allergy Clin Immunol 101: S352-356, 1998. https://doi.org/10.1016/S0091-6749(98)70218-0

DOWNIE SR, ANDERSSON M, RIMMER J, LEUPPI JD, XUAN W, AKERLUND A, PEAT JK, SALOME CM: Association between nasal and bronchial symptoms in subjects with persistent allergic rhinitis. Allergy 59: 320-326, 2004. https://doi.org/10.1111/j.1398-9995.2003.00419.x

GRATZIOU C, ROVINA N, LIGNOS M, VOGIATZIS I, ROUSSOS C: Exhaled nitric oxide in seasonal allergic rhinitis: influence of pollen season and therapy. Clin Exp Allergy 31: 409-416, 2001. https://doi.org/10.1046/j.1365-2222.2001.01001.x 
HENRIKSEN AH, SUE-CHU M, HOLMEN TL, LANGHAMMER A, BJERMER L: Exhaled and nasal NO levels in allergic rhinitis: relation to sensitization, pollen season and bronchial hyperresponsiveness. Eur Respir J 13: 301-306, 1999. https://doi.org/10.1034/j.1399-3003.1999.13b14.x

JATAKANON A, LIM S, KHARITONOV SA, CHUNG KF, BARNES PJ: Correlation between exhaled nitric oxide, sputum eosinophils, and methacholine responsiveness in patients with mild asthma. Thorax 53: 91-95, 1998. https://doi.org/10.1136/thx.53.2.91

JILMA B, KASTNER J, MENSIK C, VONDROVEC B, HILDEBRANDT J, KREJCY K, WAGNER OF, EICHLER HG: Sex differences in concentrations of exhaled nitric oxide and plasma nitrate. Life Sci 58: 469-476, 1996. https://doi.org/10.1016/0024-3205(95)02311-9

JORISSEN M, LEFEVERE L, WILLEMS T: Nasal nitric oxide. Allergy 56: 1026-1033, 2001. https://doi.org/10.1034/j.1398-9995.2001.00145.x

KHARITONOV S, ALVING K, BARNES PJ: Exhaled and nasal nitric oxide measurements: recommendations. The European Respiratory Society Task Force. Eur Respir J 10: 1683-1693, 1997. https://doi.org/10.1183/09031936.97.10071683

KROUSE JH, ROLAND PS, MARPLE BF, WALL GM, HANNLEY M, GOLLA S, HUNSAKER D: Optimal duration of allergic rhinitis clinical trials. Otolaryngol Head Neck Surg 133: 467-487, 2005. https://doi.org/10.1016/j.otohns.2005.07.024

LEE KJ, CHO SH, LEE SH, TAE K, YOON HJ, KIM SH, JEONG JH: Nasal and exhaled nitric oxide in allergic rhinitis. Clin Exp Otorhinolaryngol 5: 228-233, 2012. https://doi.org/10.3342/ceo.2012.5.4.228

LEIGH MW, HAZUCHA MJ, CHAWLA KK, BAKER BR, SHAPIRO AJ, BROWN DE, LAVANGE LM, HORTON BJ, QAQISH B, CARSON JL, DAVIS SD, DELL SD, FERKOL TW, ATKINSON JJ, OLIVIER KN, SAGEL SD, ROSENFELD M, MILLA C, LEE HS, KRISCHER J, ZARIWALA MA, KNOWLES MR: Standardizing nasal nitric oxide measurement as a test for primary ciliary dyskinesia. Ann Am Thorac Soc 10: 574-581, 2013. https://doi.org/10.1513/AnnalsATS.201305-110OC

LINHARES D, JACINTO T, PEREIRA AM, FONSECA JA: Effects of atopy and rhinitis on exhaled nitric oxide values - a systematic review. Clin Transl Allergy 1: 8, 2011. https://doi.org/10.1186/2045-7022-1-8

LUNDBERG JO, RINDER J, WEITZBERG F, ALVING K, LUNDBERG JM: Heavy physical exercise decreases nitric oxide levels in the nasal airways in humans. Acta Physiol Scand 159: 51-57, 1997. https://doi.org/10.1046/j.1365-201X.1997.68339000.x

MANISCALCO M, SOFIA M, CARRATÙ L, HIGENBOTTAM T: Effect of nitric oxide inhibition on nasal airway resistance after nasal allergen challenge in allergic rhinitis. Eur J Clin Invest 31: 462-466, 2001. https://doi.org/10.1046/j.1365-2362.2001.00825.x

NAVARRO A, VALERO A, ROSALES MJ, MULLOL J: Clinical use of oral antihistamines and intranasal corticosteroids in patients with allergic rhinitis. J Investig Allergol Clin Immunol 21: 363-369, 2011.

OLIN AC, HELLGREN J, KARLSSON G, LJUNGKVIST G, NOLKRANTZ K, TORÉN K: Nasal nitric oxide and its relationship to nasal symptoms, smoking and nasal nitrate. Rhinology 36: 117-121, 1998.

OLTHOFF A, ROHRBACH S, FABER M, GÖTZ W, LASKAWI R: Neuronal nitric oxide synthase immunoreactivity in the nasal mucosa of patients with idiopathic and allergic rhinitis. ORL J Otorhinolaryngol Relat Spec 64: 180-185, 2002. https://doi.org/10.1159/000058022

PALM JP, ALVING K, LUNDBERG JO: Characterization of airway nitric oxide in allergic rhinitis: the effect of intranasal administration of L-NAME. Allergy 58: 885-892, 2003. https://doi.org/10.1034/j.13989995.2003.00098.x

POLOSA R, CIAMARRA I, MANGANO G, PROSPERINI G, PISTORIO MP, VANCHERI C, CRIMI N: Bronchial hyperresponsiveness and airway inflammation markers in nonasthmatics with allergic rhinitis. Eur Respir J 15: 30-35, 2000. https://doi.org/10.1183/09031936.00.15103000

SERRANO C, VALERO A, PICADO C: Nasal nitric oxide (in Spanish). Arch Bronconeumol 40: 222-230, 2004. https://doi.org/10.1157/13060347

STRUBEN VMD, WIERINGA MH, FEENSTRA L, DE JONGSTE JC: Nasal nitric oxide and nasal allergy. Allergy 61: 665-670, 2006. https://doi.org/10.1111/j.1398-9995.2006.01096.x 
TAYLOR DR, PIJNENBURG MW, SMITH AD, DE JONGSTE JC: Exhaled nitric oxide measurements: clinical application and interpretation. Thorax 61: 817-827, 2006. https://doi.org/10.1136/thx.2005.056093

WANG D-Y: Treatment of allergic rhinitis: $\mathrm{H}_{1}$-antihistamines and intranasal steroids. Curr Drug Targets Inflamm Allergy 1: 215-220, 2002. https://doi.org/10.2174/1568010023344625

WILLIAMSON PA, VAIDYANATHAN S, CLEARIE K, STEWART M, LIPWORTH BJ: Relationship between fractional exhaled nitric oxide and nasal nitric oxide in airways disease. Ann Allergy Asthma Immunol 105: 162-167, 2010. https://doi.org/10.1016/j.anai.2010.05.014

WILSON AM, DEMPSEY OJ, SIMS EJ, LIPWORTH BJ: Subjective and objective markers of treatment response in patients with seasonal allergic rhinitis. Ann Allergy Asthma Immunol 85: 111-114, 2000. https://doi.org/10.1016/S1081-1206(10)62449-0

YAMADA T, YAMAMOTO H, KUBO S, SAKASHITA M, TOKUNAGA T, SUSUKI D, NARITA N, OGI K, KANNO M, YAMASHITA S, TERASAWA Y, KAYANO Y, MASADA M, FUJIEDA S: Efficacy of mometasone furoate nasal spray for nasal symptoms, quality of life, rhinitis-disturbed sleep, and nasal nitric oxide in patients with perennial allergic rhinitis. Allergy Asthma Proc 33: e9-16, 2012. https://doi.org/10.2500/aap.2012.33.3509

YUKSEL H, KIRMAZ C, YILMAZ O, PINAR E, VATANSEVER S, DEGIRMENCI PB, OZBILGIN K: Nasal mucosal expression of nitric oxide synthases in patients with allergic rhinitis and its relation to asthma. Ann Allergy Asthma Immunol 100: 12-16, 2008. https://doi.org/10.1016/S1081-1206(10)60398-5 